\title{
A LOUCURA E A REPÚBLICA NO BRASIL: A INFLUÊNCIA DAS TEORIAS RACIAIS
}

\author{
Audrey Rossi Weyler ${ }^{1}$ \\ Universidade Ibirapuera - SP
}

\begin{abstract}
O presente artigo tem como objetivo discutir as modificações nas formas de compreensão e de enfrentamento da loucura na passagem do Império para a República, levando-se em conta a influência das teorias raciais importadas da Europa a partir de 1870. A adoção desses modelos teóricos cumpriu uma série de funções sociais e políticas referente a um projeto de nação. Neste contexto, as manifestações da loucura passaram a ser associadas à doença, à degeneração e ao risco e sofreram variadas medidas de opressão justificadas "cientificamente". Até hoje, as interpretações científicas do problema da "doença mental" continuam localizando a enfermidade no paciente. Ao reduzir a doença e a sua causa a uma problemática exclusivamente pessoal, sem que se considere o contexto socioeconômico e político da sua emergência, estas explicações configuram-se como ideologia.
\end{abstract}

Descritores: Loucura. Ideologia. Saúde mental. História da PsicologiaBrasil

\begin{abstract}
A instalação do regime republicano no Brasil foi acompanhada de mudanças nas formas de compreensão e enfrentamento da loucura. Cunha (1990) verificou que, ao longo do século XIX, portadores da marca da "vesânia” circulavam nas cidades do Segundo Império. Eram os "loucos de rua”
\end{abstract}

1 Mestre em Psicologia pelo Departamento de Psicologia Social e do Trabalho e membro do Laboratório de Estudos em Psicanálise e Psicologia Social (LAPSO) do Instituto de Psicologia - USP. Docente da Universidade Ibirapuera. Endereço para correspondência: Rua Cayowáa, 2046, bloco 4, apto. 22, CEP 01258-010, São Paulo, SP. Endereço eletrônico: dreyrw@uol.com.br 
que, incorporados ao cotidiano da cidade, geralmente, encontravam aceitação popular. Personagens como o "Príncipe de Obá II”, “Chico Cambraia”, "Maria Doida”, entre tantos outros, perambulavam pela cidade, povoando o cenário e o imaginário social como figuras muitas vezes lendárias que podiam ser objeto de forte apreço popular ou motivo de riso, mas, em geral, não despertavam necessariamente medo ou desconforto aos transeuntes. Mello Moraes Filho (1979) fala da maior tolerância e possibilidade de circulação que tipos de rua, como o Príncipe Obá, encontravam nas cidades do segundo Império:

Identificado com seu papel, percorria ele as principais ruas da cidade, cumprimentando, distribuindo cortesias e afabilidades de soberano, atravessando de uma calçada para outra, a fim de trocar palavras e rápidas frases com qualquer pessoa distinta que se lhe deparava. O príncipe Obá era um negro de estatura colossal, usava empinada carapinha, bigode espesso e cavaignac. Sua voz era vibrante e harmoniosa, seu olhar dominante e altivo. (...) Empavonado em sua instância dinástica, o príncipe Obá considerava as ruas em geral como vastos salões de seus palácios, como prolongamentos pitorescos dos seus estados. (p. 309)

No entanto, à medida que se consolida o lema "ordem e progresso", esses personagens pitorescos e aceitos em sua diferença passaram a ser vistos como doentes mentais perigosos:

Conta-se que no dia 2 de dezembro, que seguiu-se à proclamação da República, o príncipe Obá, como de costume, dirigiu-se ao paço para cumprimentar o Imperador; que, encontrando as portas fechadas, ou sendo despedido, enfureceu-se e prorrompeu em 'vivas' e disparates.

O que nisso há de autêntico não afirmamos; o que é certo, porém, é que o governo provisório da República cassou-lhe as honras de alferes, sobrevivendo ele apenas alguns meses a esse desgosto. (Mello Moraes Filho, 1979, p. 309)

A medicina foi convocada a participar desse projeto de reordenamento do espaço urbano da passagem do século, o que acabou dando forma ao desenho da psiquiatria brasileira. ${ }^{2}$ Como se sabe, a história da Psiquiatria,

2 Segundo Amarante (1994), em 1830, foi realizado um primeiro diagnóstico da situação dos loucos por uma comissão da Sociedade de Medicina do Rio de Janeiro. 
com seus saberes e práticas, acompanha de perto a história das cidades (Baptista, 1999).

No panorama da abolição da escravatura, dos grandes movimentos migratórios e de crescimento das cidades, temia-se o caos urbano, a criminalidade e a inferioridade de um povo muito distante dos padrões europeus. ${ }^{3}$ Era intensa a preocupação de políticos e intelectuais em livrar a sociedade do convívio com indivíduos e grupos considerados inferiores e perigosos.

O regime republicano recém-instaurado enfrentava crescentes tensões sociais que se opunham aos governantes. No imaginário das elites, as revoltas sociais e as dificuldades econômicas resultavam da constituição étnica do povo e não de causas sociais estruturais. As teorias raciais importadas da Europa se apresentavam, neste sentido, como modelo teórico ideal para justificar o complexo jogo de interesses que se montava no país. No interior da ideologia liberal, era necessário e urgente estabelecer critérios diferenciados de cidadania (Schwarcz, 2002).

O Brasil passou a consumir modelos teóricos raciais evolucionistas e social-darwinistas que ganharam força como um novo e importante argumento para explicar a desigualdade social:

adotando uma espécie de "imperialismo interno", o país passava de objeto a sujeito das explicações, ao mesmo tempo, que se faziam das diferenças sociais variações raciais. Os mesmos modelos que explicavam o atraso brasileiro ao mundo ocidental passavam a justificar as novas formas de inferioridade. Negros, africanos, trabalhadores, escravos e ex-escravos - "classes perigosas” a partir de então - nas palavras de Silvio Romero transformavam-se em "objetos de sciencia” (prefácio a Rodrigues, 1933/88). Era a partir da ciência que se reconheciam as diferenças e se determinavam as desigualdades. (Schwarcz, 2002, p. 28)

Expressões da loucura eram encontradas nos mais diversos espaços das cidades, ora nas ruas, entregues à sorte, ora nas prisões ou nas casas de correção, ora nos asilos para mendigos. Foi apenas décadas mais tarde, ao longo do século XIX, que a loucura passou a ser considerada doença mental e merecedora de um espaço próprio para a sua reclusão e tratamento.

3 De acordo com Patto (1996), foi a partir da vinda da Corte ao Brasil que se criaram condições sociais e psicológicas para a disseminação do desejo de parecer europeu, sobretudo se assemelhar ao modelo francês. 
A mestiçagem era compreendida como responsável pela produção de um tipo híbrido, inferior física e intelectualmente. Tomada como sinônimo de degeneração não só racial como social, era a partir da miscigenação que se previa a loucura, se entendia a criminalidade e, posteriormente, se definiram programas de melhoramento da raça.

A sociedade brasileira passou a ser abordada, neste período de passagem do Império para o regime republicano, como um corpo doente e mestiço que requeria intervenção médica. Este contexto marcado por epidemias e pelo aumento das estatísticas de loucura, de criminalidade e de alcoolismo,

é a época do surgimento da figura do "médico missionário”, obstinado em sua intenção de cura e de intervenção. É também o momento do fortalecimento do perito em medicina legal, cujo olhar não recaía sobre o crime, mas sobre o criminoso, com suas taras e degenerações. (Schwarcz, 2002, p. 198)

Ao saber médico atribuiu-se, progressivamente, o papel de tutorar e sanear a nacionalidade; para o cumprimento desta "missão", os médicos assumiram uma postura na maioria das vezes marcadamente autoritária e violenta em suas intervenções. ${ }^{4}$ Segundo um dos lemas do período - "Prevenir, antes de curar" - os males deveriam ser erradicados antes mesmo de sua manifestação. Era urgente, portanto, não só curar as epidemias, mas, sobretudo, evitar o aparecimento de novos surtos. Os projetos de saneamento e de higienização começaram a tomar força, ultrapassando os limites estritos da medicina, através de medidas diretas de intervenção na realidade social. Aconteceram, neste período, grandes projetos de saneamento ${ }^{5}$ que se esten-

4 "Reação desmesurada mas reveladora da violência com que se aplicavam esses projetos de higienização foi a 'Revolta da Vacina' (1904). Apesar do acerto da medida e da vacinação obrigatória, a força da mobilização popular indicava o descompasso entre os programas científicos e a compreensão por parte do povo" (Schwarcz, 2002, p. 34).

5 A importância das campanhas de saneamento fica muito evidente na fala seguinte do médico Pacífico Pereira, diretor da Revista científica Gazeta:

“A hygiene é a primeira necessidade de um povo, e não há paiz civilizado em que não esteja radicada a comprehensão e a pratica dessa verdade. MENS SANA IN CORPORE SANO é o lemma da educação physica e mental do indivíduo, como é o 
deram a todos os espaços das cidades. Nenhum detalhe deveria escapar ao olhar de médicos e sanitaristas, que interferiam nos usos e costumes e interferiam nos hábitos alimentares, nas formas de vestir, no comportamento nos lugares públicos, na educação higiênica das crianças desde a mais tenra idade. As teses das teorias raciais ocupavam um lugar central no pensamento e na ação dos médicos preocupados com o destino da nação. Casos de embriaguez, alienação, epilepsia e desobediência civil eram tomados como prova de que o cruzamento racial leva à degeneração.

No caso da loucura, o referencial explicativo foi o biologismo da corrente psiquiátrica alemã trazido por Juliano Moreira (Amarante, 1994). A partir dessa virada de século, o alienismo, que entendia a loucura como patologia orgânica, constituiu-se como um campo de especialidade médica no país:

A questão da loucura estava, nesse momento, na ordem do dia, e as atitudes sociais em face da antiga e familiar vesânia das ruas começavam a dar sinais de mudanças. E começava a mudar em sentidos muito precisos: na constituição de um campo de especialistas, na afirmação da loucura como uma doença de fundo orgânico, da invisibilidade da doença para os leigos, da 'cura' como um objetivo e, sobretudo, da abrangência ilimitada da loucura desvinculada de suas manifestações exteriorizadas. (Cunha, 1990, p. 20)

O referencial teórico que mais influenciou o alienismo nesse período foi a teoria da degenerescência ${ }^{6}$, base da eugenia. Atribuía-se à loucura um

saneamento physico e moral do povo que constitue o vigor, a felicidade e a principal riqueza da nação... O saneamento é exigência da civilização, que o patriotismo e a humanidade estão impondo como uma necessidade inadiável" (GMB, 1899: 435- citado por Schwarcz,, 2002, p. 206).

6 Morel, enquanto era diretor do asilo de Saint-Yon, construiu a teoria da degenerescência a partir de observações do proletariado e das populações agrícolas. Tratava-se de um sistema explicativo que estabelecia uma relação de causa-efeitocausa entre a situação de doença e miséria de tal segmento populacional e o mal da degeneração. Esse mal teria como fatores etiológicos as intoxicações, especialmente devidas ao intenso uso de álcool, as influências do meio social, os temperamentos mórbidos, as influências hereditárias e enfermidades anteriores. As degenerações, segundo Morel, seriam transmitidas e agravadas hereditariamente, 
caráter hereditário, transmitida em graus crescentes através das gerações. As classes sociais inferiores, compostas por indivíduos degenerados, eram portadoras de "maus hábitos", "vícios” e "ociosidade” que alimentavam a vesânia. Esta concepção justificava a pobreza e estigmatizava os pobres. Essa teoria conferiu à medicina mental um outro patamar teórico e prático e foi uma importante aliada do enfrentamento, no início do período republicano, dos problemas urbanos trazidos pelas recentes mudanças econômicas, sociais e políticas. Nesta direção, Cunha (1990) ressalta:

o pensamento alienista aparecia, portanto, voltado para a profilaxia do meio urbano. Para eles, a cidade aparecia como ambiente ideal para esta cultura de germes deflagradores de uma verdadeira epidemia social. Se, do ponto de vista teórico, degenerados sempre existiram (pois é da natureza da 'ciência' adotar sempre pontos de vista supra-históricos), a cidade tornaria possível que eles se escondessem e se multiplicassem sem controle. (...) Esconderia multidões anônimas de degenerados em seus becos, vielas, nas casas das meretrizes, sempre solidárias com a imoralidade, nos botequins e cabarés, nas habitações coletivas e insalubres, nas multidões de pobres laboriosos cuja fronteira com os degenerados seria teórica e praticamente imperceptível. (p. 27)

Todas as formas de habitações coletivas encarnavam, neste sentido, uma espécie de "síntese do mal”, vistos como lugares de doença, imoralidade, desordem ${ }^{7}$. Suas precárias condições de higiene e ventilação constituíam

configurando, assim, um círculo vicioso, uma vez que a degenerescência levaria os indivíduos a estarem mais propensos ao mal moral, o que acabaria por imprimir novos atributos degenerados transmitidos para as gerações seguintes, até a extinção completa da linhagem.

7 Os cortiços configuravam-se, dessa forma, como o extremo oposto da família e dos ideais positivistas de ordem, disciplina e higiene. Por essa razão, foram alvos de inúmeras intervenções normativas por parte do Estado que buscavam livrar a cidade do convívio com essas habitações consideradas perigosas tanto do ponto de vista sanitário como social. No Rio de Janeiro, logo no início do século XX, Pereira Passos, com o intuito de sanear e embelezar a cidade, instaurou o famoso "botaabaixo" das habitações tidas como insalubres e indignas, além de implantar uma legislação que proibia a construção de estalagens, cortiços e que regulava as novas edificações.Na cidade de São Paulo, por sua vez, as precárias condições sanitárias dos cortiços e das moradias dos imigrantes serviram de justificativas para se instaurar o aparelho oficial de fiscalização higiênica, já em 1892, e para editar o 
uma ameaça à saúde pública, pelos riscos imediatos de contágio e propagação de epidemias, além de se estabelecerem sobre "formas promíscuas" de relacionamento, nas quais a privacidade era substituída pelo convívio de muitas pessoas em um mesmo "cômodo de dormir". Tais habitações foram tomadas, sobretudo, como abrigos para toda espécie de degenerados que "infestavam” o meio urbano. Considerações como as que seguem do secretário d’Estado dos Negócios do Interior são bastante reveladoras do modo como estas moradias e suas populações eram encaradas pelas autoridades republicanas:

Quer do ponto de vista social, quer sanitário, a higiene domiciliar merece detido exame dos poderes públicos. (...) São casas imundas o berço do vício e do crime. Os indivíduos que vivem na miséria e abrigados aos pares, em cubículos escuros e respirando gases mefíticos, que exalam de seus próprios corpos não asseados, perdem de uma vez os princípios da moral e atiram-se cegos ao crime e ao roubo de forma a perderem sua liberdade ou a ganharem por essa forma meios de se alimentarem ou dormirem melhor. ${ }^{8}$

Era estreita a aliança entre alienistas, urbanistas, engenheiros e sanitaristas no projeto de ordenar e disciplinar a vida nas cidades. Os temas referentes à cidade eram centrais, pois a multidão continha o sério risco de propagar epidemias de diversas ordens, inclusive, “psíquicas”. Cabia, então, aos alienistas a tarefa de identificar e isolar os indivíduos nocivos e degenerados, passíveis de contaminar todo o corpo social com o vírus da desordem. $\mathrm{Na}$ tarefa de livrar a sociedade da degeneração, o alienismo serviu como instrumento para o combate ao crime, imposição de disciplinas para o trabalho e moral familiar e para a higiene social. Ao imprecisar a loucura, pela impossibilidade de um claro estabelecimento de seus limites, o alienismo per-

Código Sanitário que proibia a construção de novos cortiços e estabelecia as normas de adequação higiênica das moradias. Tratava-se, portanto, de uma "profilaxia” e disciplinarização dos espaços públicos, dos corpos e dos lares, mediante o apanágio, muitas vezes violento, da saúde pública. (Marins, 1998).

8 Trecho do Relatório apresentado ao Presidente do Estado de São Paulo pelo Dr. Cesário Motta Júnior, secretário d’Estado dos Negócios do Interior, em 28 de março de 1894 (citado por Marins, 1998, p. 174). 
mitiu a intensa patologização de todo e qualquer comportamento que escapasse às normas, incluindo diferentes segmentos sociais sob suspeita.

Dentro dessa percepção do social, e em busca dos demi-fous ${ }^{9}$ e degenerados, o alienismo inicia um processo exaustivo de reconhecimento da multidão, decompondo seu universo de ameaças: criminosos e delinqüentes, prostitutas e vagabundos, jogadores, alcoólatras, negros, anarquistas, imigrantes - todos se tornam objetos de um saber que se constrói da observação dos loucos, assim como da população da cidade (Cunha, 1986, p. 51).

O Estado, preocupado com o progresso (indivíduos “saudáveis” para a produção competitiva), valeu-se da teoria da degenerescência como justificativa para o seqüestro e recolhimento de faces do proletariado em hospícios. Era preciso expulsar os alienados das ruas e do convívio social, como medida sanitária de manutenção da ordem social entendida como requisito do progresso do país.

Apoiado em uma promessa de saúde do corpo social, o internamento nos hospícios contrapunha-se à temível imagem da desordem urbana, da sujeira, da subversão dos valores mais caros às elites pela imposição de uma versão higiênica, disciplinada, pacífica e capaz de restaurar no próprio mundo do desatino a imagem da ordem almejada. Foi neste contexto e apoiado nesses ideais que os hospícios e as colônias para alienados como instituições médicas surgiram, no Brasil, como promessa de um mundo regulado que substituiria o caos da loucura pelo triunfo da razão.

A convivência entre degenerados e trabalhadores era vista como um enorme impeditivo para a higiene e saúde da população. O modo de se lidar com a loucura deixou, progressivamente, de se restringir apenas aos "procedimentos curativos e assistenciais” e se ampliou para a profilaxia e proteção da sociedade contra os degenerados, estendendo-se para toda e qualquer "superfície de emergência da loucura”. ${ }^{10}$ Ao mesmo tempo em que indiví-

9 Indivíduos a caminho da loucura, com um potencial ainda não completamente manifestado de enlouquecimento.

10 Expressão utilizada por Castel (1978/1991). 
duos tidos como degenerados eram confinados nos espaços excludentes dos manicômios, cabia à psiquiatria garantir o futuro saudável das "boas famílias brasileiras”, por meio de medidas tão violentas e autoritárias quanto o seqüestro de grandes contingentes populacionais nos manicômios. Segundo Baptista (1999), a definição moderna da loucura, que acompanhou o processo de higienização do espaço urbano, também incidiu no cotidiano burguês.

Enquanto nos hospícios amontoavam-se os desvalidos das classes populares, a mesma psiquiatria produtora dessa população confinada oferecia instrumentos de auto-conhecimento, fomentava a preocupação da busca da identidade brasileira, apresentava seus postulados para o controle e a prevenção de emoções incontroláveis, principalmente as femininas, propondo por meio de seus cuidados o futuro saudável da família burguesa. Essa dimensão tutelar penetra na cotidianidade fomentando o medo e a insegurança na apropriação autônoma do corpo, do espaço e do tempo. ( p. 121)

O discurso higienista, iniciado no final do Segundo Império, firmou-se ao longo da Primeira República. Especialmente durante as décadas de 20 e 30, a psiquiatria preventiva, que acoplou os princípios de uma "nova ciência” denominada eugenia ${ }^{11}$ a seus ideais regeneradores, ganhou ainda maior impulso. Tratava-se de um projeto político autoritário de evolução racial da nação. O eugenismo, uma espécie de prática avançada do darwinismo social, incentivou a administração científica e racional da hereditariedade, por meio de novas políticas sociais interventivas que incluíam, sobretudo, uma deliberada seleção social. O olhar médico dividia a população em doentes e sãos, em regeneráveis e não-regeneráveis, tratados de formas distintas ${ }^{12}$.

11 Termo criado pelo fisiologista inglês Galton para designar o "estudo dos fatores socialmente controláveis que podem elevar ou rebaixar as qualidades raciais das gerações futuras, tanto física quanto mentalmente” (Pequignot, Henri. "Eugénique et eugénisme”. In Encyclopedia universalis, v. 6, 1970, p. 731, citado por Costa, 1981, p. 30)

12 O primeiro grupo deveria ser educado de forma a evitar os maus hábitos e as perversões. O segundo, composto pela grande massa de doentes crônicos, tinha como principal perspectiva o desaparecimento, fosse pelo isolamento, fosse pela esterilização (Schwarcz, 2002). 
A boa recepção da eugenia nos meios psiquiátricos deveu-se à convicção de médicos e sanitaristas de que a proporção das doenças mentais era mais alta entre as "estirpes inferiores" e de que, concomitantemente, o número de nascimentos entre as "camadas superiores" estava em franco declínio. O caminho para o "abastardamento mental da espécie humana" estava, segundo os psiquiatras, traçado e só poderia ser interrompido pelas ações higienistas e eugênicas a serem aplicadas em todo o corpo social. A partir de tais práticas, seria possível prever, inclusive, o nascimento de um novo tipo de homem, sadio, vigoroso, acima de qualquer tara ou degenerescência. Se o "paraíso bíblico o homem destruiu” com “a eugenia o homem criará o paraíso terrestre”, é o que prometia Riedel repetindo a fórmula de Renato Kehl, papa do eugenismo brasileiro do período (Reis, 2000).

A década de 20, nesse sentido, foi marcada pelo surgimento de um expressivo número de ligas, associações e entidades civis voltadas para o projeto eugenista de regeneração e moralização das massas. Com o objetivo de fortalecer ainda mais a divulgação e a implementação dos programas de higiene mental e eugenia, foi fundada, em 1923, A Liga Brasileira de Higiene Mental (LBHM), por iniciativa do psiquiatra Gustavo Riedel. Nascida em um contexto político de importante mobilização social e reavivamento do nacionalismo, a LBHM voltou-se para a grande tarefa de regeneração nacional, na defesa da saúde psíquica, tanto individual, como coletiva. Os temas de ações definidos como prioritários para o cumprimento de tal tarefa foram: o combate ao alcoolismo e ao mais diversos “vícios sociais"; imigração selecionada; segregação eugênica de ex-alienados; seleção e orientação profissional com vistas à racionalização do trabalho; esterilização compulsória dos indivíduos classificados como degenerados; controle dos casamentos (para incentivar as uniões consideradas como eugenicamente desejáveis e dificultar aquelas tidas como indesejáveis ou inadequadas) (Reis, 2000). Buscavase, portanto, uma "neutra solução científica" para uma sociedade marcada por inúmeros conflitos.

Num movimento de conjugar esforços de diferentes especialidades, os teóricos do totalitarismo brasileiro, redescobridores de Gobineau, do racismo biológico e de concepções orgânicas da sociedade, fizeram coro com o 
discurso médico. Nesse sentido, propostas como a do neuropsiquiatra Alberto Farani acerca da esterilização dos doentes mentais e a campanha de Renato Kehl e Xavier de Pliveira contra imigrantes nacionais e estrangeiros encontravam justificativas científicas e terreno fértil.

Se os fracos, na opinião da elite respaldada pelas construções teóricas da eugenia, impregnavam a sociedade e impediam o progresso, todas as propostas e práticas filantrópicas ou humanitárias deveriam ser combatidas, pois mantinham e protegiam exemplos inferiores ${ }^{13}$ e prejudicavam o aperfeiçoamento da raça humana ao se contraporem à natural racionalidade social.

A LBHM, inicialmente voltada para a melhoria da assistência psiquiátrica, alterou sua orientação, principalmente a partir de 1931, para a prevenção da doença mental, sendo agora o indivíduo normal e a saúde social seus focos de atenção e não mais apenas aqueles indivíduos considerados doentes. A eugenia, desde essa época, passou a ser considerada "higiene social da raça” e a higiene mental como uma aplicação de seus princípios à vida social. Cabia ao eugenista proteger a evolução da espécie das nocivas ações de certos indivíduos ou grupos sociais.

Nesta passagem do foco de atuação do indivíduo para a sociedade, da prática asilar para práticas preventivas, da degeneração para a possibilidade de “ressurgimento da raça”, as Ligas de Higiene Mental depararam-se com a necessidade de reformular dispositivos institucionais, de forma a adaptá-los

13 Construções como as de Renato Kehl são emblemáticas da imensa carga preconceituosa imbricada nessas teorias consideradas totalmente científicas: "Evidencia-se por toda a parte a preoccupação dos governos de encontrar soluções para abrigar e alimentar a elevadíssima percentagem de incapazes, de mendigos, de criminosos, de anormais de todo o gênero que difficultam e oneram, pesadamente, a parte sã e produtiva da sociedade.São estes reflexos que impellem os eugenistas do mundo inteiro a uma campanha intensiva em prol da parte sadia dos nossos semelhantes, propondo leis de preservação racial e se esforçando para o estabelecimento de medidas que atenuem os efeitos das praticas humanitárias (aliás louváveis sob o critério sentimental), feitos pelas administrações públicas e pelas associações philantrópicas em favor dos que, sob a lei natural, teriam de desaparecer” (Kehl, R.(1931, mar,/abr./maio). A campanha da eugenia no Brasil. Arch. Bras.de Hygiene Mental, 4(3), 93-99, citado por Costa, 1981, p. 42). 
aos novos propósitos da eugenização. O desafio colocado, neste contexto, era o de criar uma rede institucional que comportasse não só as internações, mas que atingisse igualmente a "imensa legião de psychasthenicos, melanchólicos, psychopatas accidentaes que transitoriamente, em conseqüência de doenças infecciosas, intoxicações ou fatores de ordem moral (...) apresentam distúrbios sensoriais." ${ }^{14}$

O programa de intervenção no espaço social construído pelo Liga Brasileira de Higiene Mental era eugenista, xenófobo, antiliberal e racista (Costa, 1981). Essas características traziam um impasse aos intelectuais brasileiros, não só porque tinham na base um pessimismo em relação às possibilidades do país, mas também porque os colocava numa posição existencial dramática, pois eles próprios eram frutos de um povo mestiço (Cândido, citado por Reis, 2000). A situação exigiu uma acomodação dos pressupostos do darwinismo social e do evolucionismo social de modo a justificar a hierarquia social sem perder de vista a viabilidade de um país de degenerados (Schwarcz, 2002).

Estes modelos que serviram de apoio à construção de concepções da vida psíquica têm como essência o encobrimento da dimensão social e política da vida humana, pois reduzem ao plano bio-psíquico uma concepção abstrata e ideológica de "ser humano".

Segundo Chauí (1981), o discurso ideológico mantém a ilusão necessária ao exercício de poder entre classes sociais, submetendo ou justificando a exclusão dos indesejáveis ou desnecessários ao capital. Os loucos, enquanto importantes representantes de segmentos econômica e socialmente "improdutivos”, foram alvos de uma série de medidas "cientificamente” justificadas de exclusão dos espaços da cidade. A localização da loucura no indivíduo favorece o "esquecimento” do que se diz através dela e, sobretudo, do contexto no qual ela surge.

14 A. C. Pacheco e Silva, (1937). Necessidade de creação de serviços abertos para a internação voluntária de psychopatas, de ambulatórios, dispensários e de uma clínica psychiátrica em São Paulo. Arquivos Paulistas de Hvgiene Mental, citado por Cunha, 1986. 
A Loucura e a República no Brasil: a Influência das Teorias Raciais

Segundo Patto (2000), a ciência e os cientistas

capturados eles também pela aparência como ideologia onipresente que aprisiona o indivíduo numa organização compacta, vinculam-se à sociedade como dado, identificam a ciência com forças produtivas, tornam-se prisioneiros das idéias que dificultam a compreensão do real, julgam-se esclarecidos sem sê-lo e portam inscientes a debilidade ética que marca as formações capitalistas. É assim que, de instrumento esclarecido, o conhecimento torna-se espelho no qual indivíduo e sociedade coincidem, restando ao homem a tarefa de adaptação ao que existe. (p. 173)

A loucura reduzida à categoria de “doença mental” é emblemática da ideologia como representação imaginária da vida social. Por ser lacunar, essa modalidade de discurso silencia as relações de exploração e violência que marca as relações nas sociedades de classes. Nelas a ciência está implicada nas relações de poder. A ideologia como discurso competente é a versão instituída, socialmente autorizada, que só pode ser tomada como verdadeira por ter deixado de lado sua determinação histórica.Trata-se de um discurso aparentemente "impessoal”, “neutro”, por estar supostamente fundado na objetividade dos fatos. Nesta esfera,

a linguagem sofre uma restrição que poderia ser assim resumida: não é qualquer um que pode dizer a qualquer outro qualquer coisa em qualquer lugar e em qualquer circunstância. O discurso competente confunde-se, pois, com a linguagem institucionalmente permitida ou autorizada, isto é, com um discurso no qual os interlocutores já foram previamente reconhecidos como tendo o direito de falar e de ouvir, no qual os lugares e as circunstâncias já foram predeterminados para que seja permitido falar e ouvir e, enfim, no qual o conteúdo e a forma já foram autorizados segundo os cânones da esfera de sua própria competência. (...) A condição para o prestígio e para a eficácia do discurso da competência como discurso do conhecimento depende da afirmação tácita e da aceitação tácita da incompetência dos homens enquanto sujeitos sociais e políticos. (Chauí, 1981, pp. 7-11)

Neste mesmo sentido, Frayze-Pereira (1982) afirma que a noção de competência marca a desigualdade entre os que detém saber e os demais homens e torna invisível a dominação. O louco, especificamente, enfrenta sérias dificuldades para se opor àquele que o exclui, uma vez que todos os seus atos assumem significados marcados pelo pressuposto da doença, são enquadrados como patologia. Ele passa a ser aquilo que o "discurso compe- 
tente" - o discurso dos únicos autorizados a dizer - diz sobre ele. Seu discurso foi silenciado pela ciência. Não mais o discurso do louco e sim o discurso sobre a loucura e os alienados. Essa manobra de silenciamento, diz este autor, não foi meramente médica, mas, sobretudo, política.

Transitamos, portanto, por um complexo terreno marcado pela instalação de uma profunda clivagem entre a "sociedade sadia e todos aqueles que, como os loucos, os delinqüentes e as prostitutas acabam produzindo desvios e doenças que, supõe-se, não têm nada a ver com a estrutura social”. É preciso considerar que a sociedade se auto-defende, não apenas dos loucos, dos delinqüentes e das prostitutas, mas, sobretudo, de sua própria loucura, de sua própria delinqüência, de sua própria prostituição. Dessa maneira, ela as coloca fora de si mesma, tratando-as como se fossem estranhas e não lhe pertencessem, estabelecendo uma marcante segregação que é, na maioria das vezes, feita por nossos conhecimentos e instrumentos de intervenção (Bleger, 1989, p. 50).

Mais de um século se passou desde a Proclamação da República do Brasil, muitas outras teorias, além dos modelos raciais, foram importadas do chamado Primeiro Mundo para tentar compreender, explicar e intervir sobre os rumos do nosso "eterno país do futuro". Deparamo-nos, atualmente, com inúmeras construções "científicas", "modernos discursos psi” que não tratam exatamente dos loucos, mas dos "hiperativos", dos "borderlines”, dos portadores de déficits de atenção, entre outras tantas nomenclaturas recentes. É importante considerar que apesar do advento das teorias críticas ao campo de estudo da loucura, boa parte das interpretações científicas do problema da “doença mental” continua objetificando-a:

A ideologia médica, ao definir a loucura como uma doença e ao difundir a imagem da doença como uma infelicidade que acontece por acaso e não como, na maioria dos casos, uma conseqüência de uma situação socioeconômica bem definida, permite tirar das perturbações psicológicas e outros comportamentos desviantes a sua dimensão social para as reduzir a uma problemática pessoal, privatizada, que apenas diz respeito à pessoa atingida. (Fleming, 1976, p. 8, citado por Scarcelli, 1998, p. 126) 
É preciso considerar, no entanto, que a produção científica não se dá de maneira linear, mas também por meio de rupturas. Neste sentido, é possível afirmar que as ideologias médicas da Psiquiatria e da Psicologia, apesar de sua hegemonia, encontraram duras críticas e questionamentos, principalmente nas décadas que se sucederam a Segunda Grande Guerra. A partir do horror ao genocídio, aos campos de concentração e às atrocidades do nazifascismo, críticas radicais à sociedade e às suas instituições foram construídas por autores como Laing, Foucault, Cooper e Basaglia, que têm como denominador comum o repúdio às práticas manicomiais de violência e opressão que encontravam justificativas “científicas” para a sua atualização. Apesar de as muitas diferenças que os separam, todos eles realizaram uma importante ruptura com os pressupostos teóricos e metodológicos da Psiquiatria e da Psicologia oficiais, ao colocarem "no cerne [de suas teorias] o desvelamento do arbítrio e do compromisso com o disciplinamento instalados no coração das instituições de prevenção e cura, a serviço de uma ordem social que vai ao encontro dos interesses do capital” (Patto, 1999, p. 110).

A construção dessas modalidades de críticas à Psicologia e à Psiquiatria, que tiveram e ainda têm ampla repercussão entre os pensadores brasileiros, aproximam-se do que Martins (1977) caracteriza como um movimento que procura situar o conhecimento, ir à sua raiz, em busca de seus compromissos sociais e históricos. Segundo o autor a "perspectiva crítica pode, por isso, ultrapassar ao invés de simplesmente recusar, descobrir toda a amplitude do que se acanha limitadoramente sob certos conceitos, sistemas de conhecimentos e métodos” (p. 2).

Escrever a história da Psiquiatria e da Psicologia desta perspectiva desvela suas lacunas discursivas, mesmo diante de mudanças teóricas e práticas dessas ciências, pois elas podem ser apenas atualizações de mecanismos repressivos sob formas mais brandas e sob dispositivos modernos que instauram outros meios de violência. Fernandes (1999) nos alerta para o desafio de extinguir os manicômios e de construir novas modalidades de enfrentamento da loucura. Desafio este que nos impele a desvendar as brechas através das quais processos "manicomiais" continuam a se insinuar sob vestes de novos discursos e novas práticas. Trata-se, em última instância, do compro- 


\title{
misso de construção de um outro lugar social da loucura que não seja o da doença, da anormalidade, da incompetência e falta de obra.
}

Weyler, A. R. (2006). Insanity and republic in Brazil: the influence of racial theories. Psicologia USP, 17 (1), 17-34.

\begin{abstract}
This article aims to discuss the various ways in which insanity was understood and dealt with in the transitional period from Empire to Republican form of government in Brazil, considering the influence of racial theories imported from Europe hence 1870. The adoption of those theoretical models have played a series of social and political roles with regard to a project of nation-building. In this context, the manifestations of insanity became associated with disease, degeneration and risk and thus submitted to various "scientifically" justified rules of oppression. Until today the scientific interpretations of the problem of "mental disease" continue to ascribe the illness to the patient. By limiting the disease and its cause to a range of problems that are exclusively personal, without considering the social, economical and political context of their emergence, those explanations establish an ideology.
\end{abstract}

Index terms: Madness. Ideology. Mental helth. History of Psychology Brazil

Weyler, A. R. (2006). La folie et la république au Brésil: l'influence des théories raciales. Psicologia USP, 17 (1), 17-34.

Résumé: Cet article a pour but la discussion des changements concernant les formes de compréhension et d'affrontement de la folie lors de la transition de l'Empire à la République au Brésil, tout en tenant compte de l'influence des théories raciales importés de l'Europe depuis 1870. L'adoption de ces modèles théoriques a joué un nombre de fonctions sociales et politiques à l'égard d'un projet de nation. Dans ce contexte, les manifestations de la folie ont commencé à être associés à la maladie, à la dégénération, au risque, et ont fait l'objet de plusieurs procédés d'oppression justifiés du point de vue "scientifique". Jusqu'à présent, les interprétations scientifiques de la question de la "maladie mentale" placent 
toujours la maladie sur les patients. Par le fait de circonscrire la maladie et sa cause à une problématique exclusivement personnelle, sans tenir compte du contexte socio-économique et politique lors de son émergence, ces explications prennent la forme d'une idéologie.

Mots-clés: Folie. Idéologie. Santé mentale. Histoire de la psychologie Brésil

\section{Referências}

Amarante, P. (1994). Asilos, alienados, alienistas: uma pequena história da psiquiatria no Brasil. In P. Amarante (Org.), Psiquiatria social e reforma psiquiátrica (pp. 7385). Rio de Janeiro: Fio Cruz.

Baptista, L. A (1999). A cidade dos sábios: reflexão sobre a dinâmica social nas grandes cidades. São Paulo: Summus.

Bleger, J. (1989). Psicologia da conduta. Porto Alegre: Artes Médicas.

Bosi, E. (1992). Entre a opinião e o estereotipo. Novos Estudos CEBRAP, (32), 111-118.

Castel, R. (1991). Ordem psiquiátrica: a idade de ouro do alienismo. Rio de Janeiro: Graal. (Trabalho original publicado em 1978)

Chaui, M. S. (1981). Cultura e democracia. O discurso e outras falas. São Paulo: Moderna.

Costa, J. F. (1981). A história da psiquiatria no Brasil - um recorte ideológico. Rio de Janeiro: Xenon.

Cunha, M. C. P. (1990). Cidadelas da ordem: a doença mental na República. São Paulo: Brasiliense.

Cunha, M. C. P. (1986). O espelho do mundo: Juquery, a história de um asilo. Rio de Janeiro: Paz e Terra.

Fernandes, M. I. A. (1999). Uma nova ordem: narcisismo expandido e interioridade confiscada. In M. I. A. Fernandes, I. R. Scarcelli \& E. S. Costa (Orgs.), Fim de século: ainda manicômios? (pp. 39-46). São Paulo: IPUSP.

Frayze-Pereira, J. A. (1982). O que é loucura. São Paulo: Brasiliense.

Koda, M. (2002). Da negação do manicômio à construção de um modelo substitutivo em saúde mental: o discurso de usuários e trabalhadores de um Núcleo de Atenção 


\section{Audrey Rossi Weyler}

Psicossocial. Dissertação de Mestrado, Instituto de Psicologia, Universidade de São Paulo, São Paulo.

Marins, P. C. G. (1998). Habitação e vizinhança: limites da privacidade no surgimento das metrópoles brasileiras. In N. Sevcenko (Org.), História da vida privada no Brasil, 3 - República: da Belle Époque à Era do Rádio (pp.131-214) São Paulo: Companhia das Letras.

Martins, J. S. (1977). Introdução à sociologia e sociedade. Rio de Janeiro: Livros Técnicos.

Mello Moraes Filho. (1979). Festas e tradições populares no Brasil. Belo Horizonte: Itatiaia.

Patto, M. H. S. (1996). Teoremas e cataplasmas no Brasil Monárquico - O caso da Medicina Social. Novos Estudos CEBRAP, (44), 180-199.

Patto, M. H. S. (1999). Formação profissional, compromisso político e luta antimanicomial. In M. I. A. Fernandes, R. Scarcelli, \& E. S. Costa (Orgs.), Fim de século: ainda manicômios? (pp. 109-122). São Paulo: IPUSP.

Patto, M. H. S. (2000). Mutações do cativeiro: escritos de psicologia e política. São Paulo: Hacher: EDUSP.

Reis, J. R. F. (2000). Raça, nação e psiquiatria: o projeto eugênico da Liga Brasileira de Higiene. In Amarante, P. (Org.), A loucura da história (pp 130-151) Rio de Janeiro: LAPS/ENSP/FIOCRUZ.

Scarcelli, I. R. (1998). O movimento antimanicomial e a rede substitutiva em saúde mental: a experiência do município de São Paulo (1989-1992). Dissertação de Mestrado, Instituto de Psicologia, Universidade de São Paulo, São Paulo.

Schwarcz, L. (2002). O espetáculo das raças. Cientistas, instituições e questão racial no Brasil. 1870-1930. São Paulo: Companhia das Letras.

Recebido em: 24.03.2006

Aceito em: 3.04.2006 